This system apparently extends into the region of the vacuum spectrograph, but until now I have not been able to make any attempt to photograph them there.

Wilson College, Bombay, 7, R. K. AsUNDI. Nov. 14.

1 NATURE, 125, 858; 1930.

s C.R., 179, 1156 ; 1924 , etc.

An Unusual Sex-Ratio in Red Deer.

I $T$ is the practice among stalkers in the deer forests of Scotland to shoot a certain proportion of the hinds each year after the stag-shooting season has finished. So far as possible the hinds chosen are those called 'yeld' or dry hinds. A 'yeld' or dry hind is one which did not have a calf during the preceding season. It may either never have had a calf or may have missed a season. Consequently the 'yeld' hinds have no calf following them. They are almost always pregnant at the time they are shot.

In September 1927, whilst staying at Langwell, Caithness, I was informed by H.G. the Duke of Portland, K.G., of a very wide-held belief amongst deer stalkers that these 'yeld' hinds always had a male embryo in the uterus and never a female. The Duke, being interested in this matter, sent me six pregnant uteri from 'yeld' hinds shot at the end of 1927. On opening them it was found that five of the embryos were male and one female.* In 1928 I received 17 uteri. Apparently the hirrds had been shot much earlier in the season, for in none of these cases was it possible to determine the sex by ordinary visual examination. The genital glands from the base of the kidney were accordingly sectioned, and it was taken that the presence of testicular tissue was positive evidence that the embryo was a male. Of the 17 uteri, one proved not to contain an embryo at all, and in 3 other cases identification was impossible. The remaining 13 embryos were all male.

It will be seen that of the cases examined, in which it was possible to sex the embryos, 18 were males and only one female.

I feel bound to mention that on arrival at Langwell in $1928 \mathrm{I}$ was informed by the stalkers that one of the 1927 uteri had been sent by mistake, and that it was in all probability not taken from a 'yeld' hind; but even without relating this to the single female in the 1927 cases, the figures appear sufficiently striking.

I am deeply grateful to the Duke of Portland, not only for his original suggestion, and for sending the specimens, but also for the kindly interest he has taken throughout.

I am also greatly indebted to Dr. H. S. Davidson and Dr. J. S. Sturrock, of the Obstetrical Department of the University of Edinburgh, who prepared the sections of the sex glands; and to Prof. Arthur Robinson, of the Anatomy Department of the University of Edinburgh, who finally identified the preparations.

The Jessop Hospital for Women,

Gell Street, Sheffield,

Dec. 24.

* The Duke incorporated these results in a letter on this subject published in the Field.

\section{Behaviour of a New Species, Digitalis mertonensis.}

HyвRIDs have often been obtained between Digitalis purpurea and $D$. ambigua, but it was not until 1926 that a few $F_{2}$ seedlings were raised by crossing such hybrids inter se. ${ }^{1}$

These seedlings were giant, highly fertile, and showed no segregation of the parental characters. They had
112 chromosomes and arose by a suppression of the reduction division in their parents, each of which had 56 chromosomes. The inference was drawn that, as in other cases, it was the doubling of the chromosome number that determined the regular pairing of identical chromosomes, the formation of uniform germ cells, and consequently fertility.

The new form has been carried on for five generations and remains giant and tetraploid. The linear measurements of the flowers are $\sqrt[3]{2}$ times those of the diploid hybrid. It throws about a quarter of less fertile forms at each generation. These are presumed to arise through the occasional pairing and segregation of the homologous chromosomes derived from the opposite parents, as in Primula kewensis. ${ }^{2}$

It crosses with the parental species, readily with $D$. purpurea, less readily with $D$. ambigua, but yields offspring which, being triploid, are highly sterile. There is no difficulty, therefore, in preserving the new form effectively uncontaminated by crossing, and we consider that it can conveniently be regarded as a new species : Digitalis mertonensis.

Amongst the rare seedlings of $D$. mertonensis $\times D$. ambigua was one small sterile plant showing all the characteristics of the $F_{1}$ hybrid and none of the characteristics of the back-cross. This plant proved to be diploid. At meiosis its chromosomes failed to pair, as in the original hybrid. It can only have arisen from an unfertilised germ-cell of its female parent, that is, by parthenogenesis. Thus the halving of the chromosome number is associated with the removal of all the conditions associated with the doubling.

Since we see that (1) the halving of the chromosome number is directly determined by omission of fertilisation (an intercellular phenomenon), while the doubling of the chromosome number is directly determined by the omission of reduction (an unrelated, intracellular phenomenon), and (2) in both cases the difference between high and low chromosome number is associated with the difference between fertility and sterility, it follows that the change of chromosome number is the cause of the change of fertility rather than a parallel effect of a common cause.

B. H. Buxton.

C. D. Darlington.

John Innes Horticultural Institution, Merton Park, London, S.W.19, Dec. 16.

1 Buxton and Newton, $J$. Genet., 19.

The Designation of Women Biologists.

I was very glad to see from Prof. Cockerell's letter in Nature of Dec. 20, that scientific men now realise the importance of continuity in a woman's name. When I first married in 1911 and kept my own name I had to overcome the opposition of a number of the leading scientific people of that day, who bitterly objected to my utilising the laws of our country, which permit a woman not only to use her maiden name throughout her married life, but also retain it as her only legal name. The Royal Society even refused to continue a grant which I had from it unless I adopted. my husband's name! So may I, as one who persistently kept her own name for scientific work (and has borne the brunt of the difficulty of doing so against an unreasoning antagonism), welcome and support Prof. Cockerell's suggestion that all women should do so ?

Heatherbank, Hindhead, Marie C. Stropes. Surrey, Dec. 30.

$$
\text { No. 3194, VoL. 127] }
$$

